\title{
Functional behavior of workers and employees in the industrial disaster prevention system
}

\author{
Tatiana Bashkireva ${ }^{1, *}$, Anastasia Bashkireva ${ }^{1}$, Alexander Morozov ${ }^{2}$, Larisa Baykova $^{1}$, and \\ Natalya Ermakova $^{3}$ \\ ${ }^{1}$ Ryazan State University named after S.A. Yesenin, associate professor, st. Svobody, 46, 390000, \\ Ryazan, Russia \\ ${ }^{2}$ Research Institute of the of the Federal penitentiaryservice of Russia, Narvskaya St., 15 A, b. 1, \\ 125130, Moscow, Russia. \\ ${ }^{3}$ Peoples' Friendship University of Russia, st. Miklukho-Maklaya, 8, 117198, \\ Moscow, Russia
}

\begin{abstract}
The study of the functional behaviour of workers and employees in the industrial disaster prevention system is a relevant research topic. Situations related to the human factor require the development of psychodiagnostic techniques that are sensitive to the state of the body and ensure the safety of the production process. Our research results show that men aimed at solving production problems solve them faster, more efficiently than they solve women faster, and more efficiently than women do. Men focused on emotions, experience significantly more emotional burnout in professional activities. Most men and women working in the workplace have an average level of coping with stress. In male workers, in fulfilling professional tasks, stable adaptation arises. They often find themselves in various extreme conditions/situations than male employees and contributes to the resistance of workers to a complex of stress factors of various nature.
\end{abstract}

\section{Introduction}

Studying the functional behaviour of production workers is of current importance. The problem of the prevention of technological disasters associated with the human factor is extremely important for society. The functional behaviour of a person is determined by the functional state in the conditions of performing professional labour activity, depending on its complexity and specialization [1]. A functional state is an integral characteristic that allows a living organism to adapt effectively to changing environmental conditions within its psychophysiological resources. [2-4]

Prevention of technological disasters is a system of measures that helps prevent the occurrence and spread of negative phenomena associated with objects (violation of the rules and instructions for safety procedures, deterioration of equipment, equipment, etc.), subjective and personal factors. [5] Subjective factors are associated with the development of social values of the profession in the educational environment. Personal factors include

\footnotetext{
* Corresponding author: bashkireva32@gmail.com
} 
the totality of personality characteristics that enable them to achieve success in mastering the profession. Three main components of personality characteristics in professional activity can be distinguished [6]: 1) professional readiness to manage conditions or situations, including extreme ones; 2) co-ownership with stress; 3) correction of post-stress conditions.

The prevalence of stressful conditions that affect functional behaviour among representatives of various professions sharply poses the problem of diagnosing the causes of stress and ways to overcome it. Neglect of such information leads to an overestimation of opportunities, inappropriate behaviour and erroneous actions in stressful production situations, that is, to the human factor. [7]

American psychologists undertook the creation of diagnostic tools for identifying stressful factors $[8,9]$. They identified three groups of events of negative content.

- Ordinary everyday events (daily hassles), causing discontent, frustration, frustration. These micro-stressors are dangerous because regular experiences lead to a cumulative effect.

- Life changes in which for various reasons a person falls (life change units). This may be a divorce, moving to another city; change of work; financial debt; the economic crisis in the country; conflict with the law; health problems of loved ones, etc. They occur in every person as single events, but they are significant, require strength and adaptation to the situation that has arisen.

- Catastrophic events in society affecting the life of each member to a greater or lesser extent. These include natural (hurricanes, floods, fires, earthquakes, pandemics, etc.) and social (military clashes, industrial and road incidents, etc.) phenomena.

All of the above conditions, external and internal stressogenic factors complicate human behavioural actions. There is a high probability of the occurrence of such situations that can lead to man-made/industrial disasters of an unintentional nature.

In this regard, the goal of our research to study the functional behaviour of employees and workers in the system for the prevention of technological disasters at work.

\section{Materials and method}

In the system for the prevention of technological disasters, diagnostics of a person's functional behaviour and methods of coping with stress under new conditions are important. In Russia, methods have not been sufficiently developed to study the increasing stress of physiological, psychological, and behavioural dysfunction in professional activities. Yu.L. Yeryomkin developed a methodology for diagnosing daily events for Russian conditions "Ryazan scale for assessing the ability to cope with stress" (RSHSSS) [10]. The technique designed to measure the level of formation of the individual's ways of coping with stress. The author identifies ways: a) orientation to the adoption, search and solution of the problem, include scales: self-control, positive reassessment, planning the solution to the problem, acceptance of responsibility; b) focus on emotions (fear, anger, panic, etc.), includes scales: confrontation, the search for public support, distance, mental avoidance.

The data are mathematically processed with the calculation of the main parameters $\mathrm{M} \pm$ $\mathrm{m} ; \pm \delta$ and statistically using the multiple regression method in the software Statistica6.0.

The sample was 94 people (55 men and 39 women) was examine, 46 of them were workers and 48 were employees aged 25-45. The indicators were measured at rest at workplaces of various industries 


\section{Results and discussion}

According to the data obtained, three groups of men and women employees and workers with high, medium and low levels of coping with stress, focused on the problem and emotions, was identified. It was revealed that the majority of men and women, office workers and workers have an average level of development of coping with stress on both the problem and the emotions.

A high level of readiness to cope with stress, problem-oriented, were identified in $16.7 \%$ of male employees, $35.3 \%$ of workers. Among women employees and workers, only $5.9 \%$ have a high level of focus on solving the problem. In the production situation, only employees of $5.5 \%$ of men and $31.5 \%$ of women are emotionally oriented toward solving problems. Among the workers and women workers, such a group were not identified.
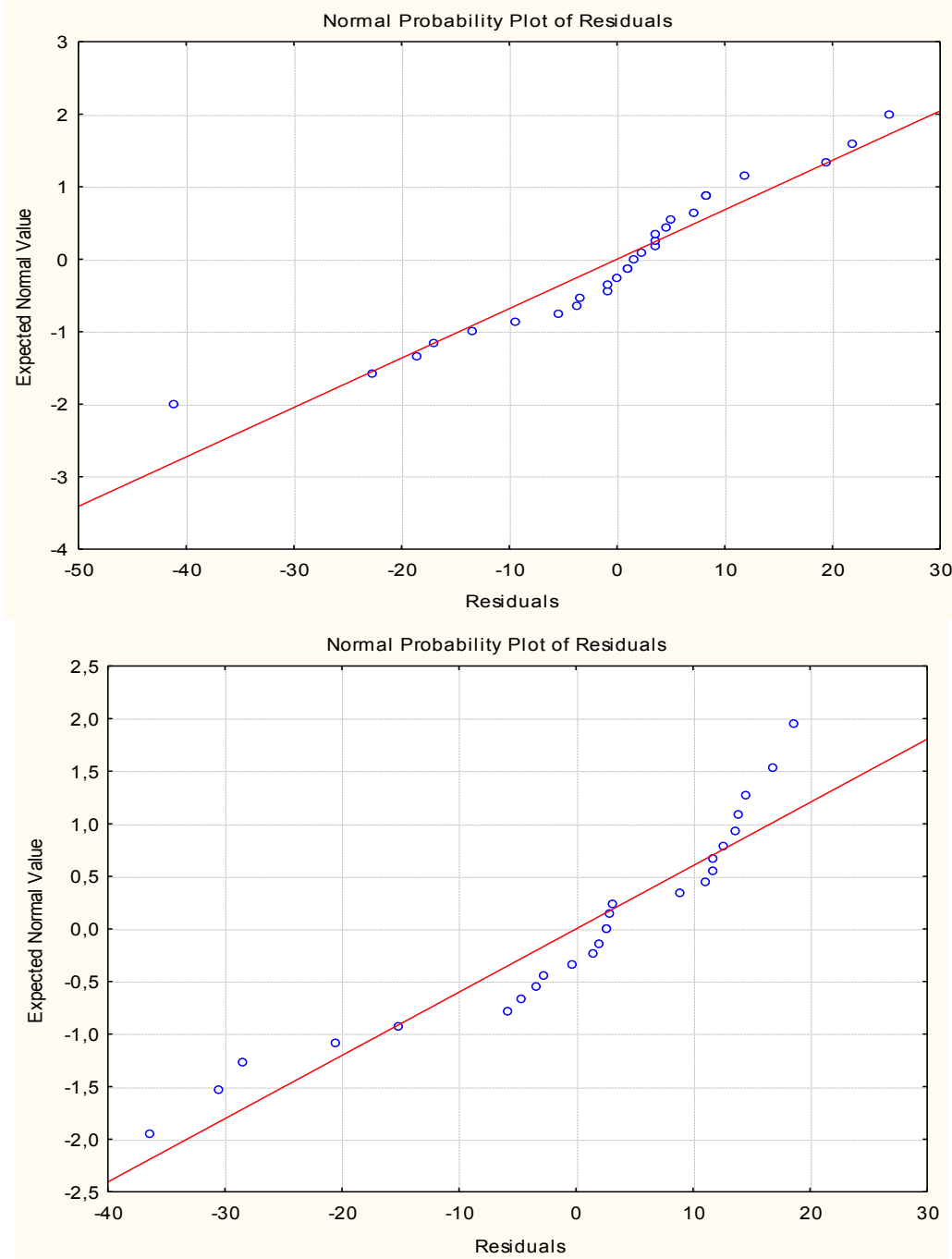

Fig. 1. The relationship between the indicators focus on solving the problem and the emotions of male employees (1) and workers (2) in the conditions of performing professional activities in production. 
Regression analysis shows a reliable relationship in male employees between a problem-solving orientation and emotions $(\mathrm{R}=0.624 ; \mathrm{P}<0.353)$. This indicates that for male employees, the higher the level of emotions, the higher the focus on solving production situations. The workers did not reveal a relationship between these indicators $(\mathrm{R}$ $=0.153 ; \mathrm{P}>0.0031)$. Consequently, in professional activities, men are more prone to emotional burnout than workers (Fig. 1).

In women employees and women workers, no relationship was found between indicators of problem-solving orientation and emotions $(\mathrm{R}=0.254 ; \mathrm{P}<0.000$..) (Fig. 2).
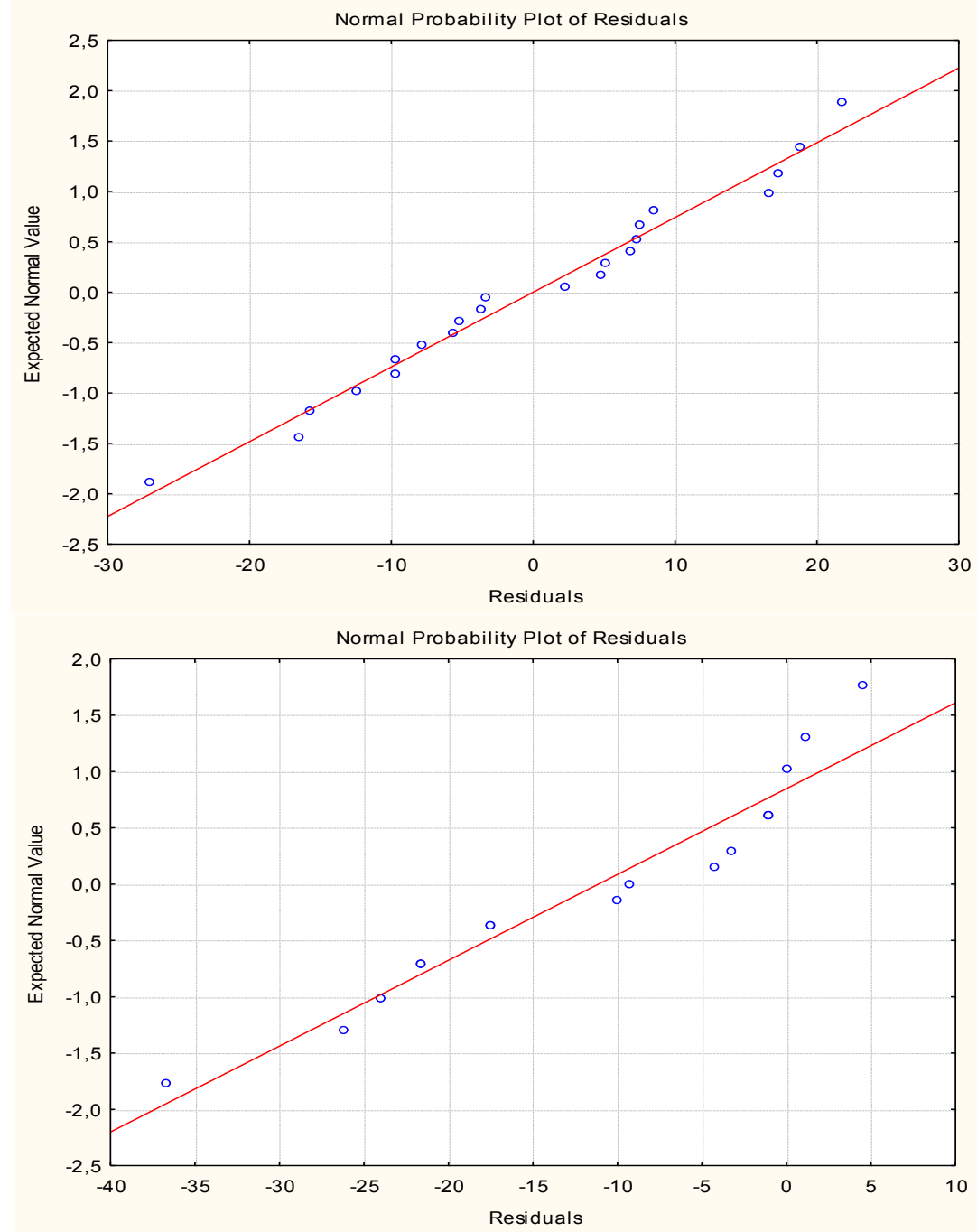

Fig. 2. The relationship between the indicators focus on solving the problem and the emotions of women employees (1) and workers (2) in the conditions of performing professional activities in production.

The data obtained are interesting in that women in production conditions while performing professional activities, are not oriented towards making independent decisions in difficult situations. However, women, regardless of their professional status, were significantly more $(\mathrm{t}=4.21 ; \mathrm{P}<0.001)$ focused on emotions and the regulation of negative 
emotional consequences of the stressor than men. We found that in women employees under professional conditions, the orientation to emotions is significantly higher $(\mathrm{t}=2.51 ; \mathrm{P}$ $<0.05)$ than in women workers. This indicates that women employees are more likely to experience stressors and perceive them emotionally.

\section{Conclusion}

Thus, the results of the study show that men aimed at production problems solve them faster, more efficiently than they solve women faster, and more efficiently than women. Men focused on emotions experience significantly more emotional burnout in professional activities. Most men and women, office workers and workers have an average level of development of coping with stress on the problem and emotions. Male workers showed a significantly high willingness to cope with stress, focused on both solving production problems and managing their emotions. We suppose that steady adaptation in male workers to fulfil professional tasks arises because they are more likely to find themselves in a variety of extreme conditions (situations), in contrast to male employees. Which accordingly increases their resistance to a complex of stress factors of various nature. Women, regardless of their professional status (employees and workers), are significantly more oriented toward emotions and the regulation of negative emotional states.

The results of the study suggest that male employees who are focused on emotions in solving production situations make more mistakes, which can lead to man-made disasters. Therefore, it is advisable to recommend for key positions in the production process employees who are focused on making and finding solutions in unusual situations and workers who have experience in solving various extreme production situations. The results obtained suggest that in the development of a system for the prevention of technological disasters and the human factor, regardless of production specialization, one should take into account gender and professional-status differences in functional behaviour in coping with stress, oriented towards making and effective decision-making.

\section{References}

1. T.V. Bashkireva, Yu.L. Yeryomkin, Gender differences in the functional behaviour of employees and workers in the prevention of technological disasters, Russian Scientific Journal 5, 339-343 (2014)

2. N.A. Agadzhanyan, T.V. Bashkireva, A.E. Severin, Gender differences in adaptive reactions in individuals with varying degrees of the tension of professional activity, Russian scientific journal 3(34), 305-309 (2013)

3. Y. Changmin, Stress coping and mental health among adolescents: applying a multidimensional stress coping model, Children and Youth Services Review ⒐9, 43-53 (2019) https://doi.org/10.1016/j.childyouth.2019.01.030

4. M. Cavalcanti, S. Abreu, R. de Jesus, C. Andrade, Dealing with wicked problems in socio-ecological systems affected by industrial disasters: A framework for collaborative and adaptive governance, Science of The Total Environment 694, 133700 (2019) https://doi.org/10.1016/j.scitotenv.2019.133700

5. K.C. Herman, S.L. Prewett, C.L. Eddy, A. Savala, W.M. Reinke, Profiles of middle school teacher stress and coping: Concurrent and prospective correlates, Journal of School Psychology 78, 54-6 (2020) https://doi.org/10.1016/j.jsp.2019.11.003 
6. S. Folkman, Manual for the ways of the coping questionnaire (Consulting Psychologist Press, 1988)

7. S. Gonsalves, P.A. Deuster, Physiological and Psychological Fatigue in Extreme Conditions: Overtraining and Elite Athletes PM\&R 2, 5, 442-450 (2010) https://doi.org/10.1016/j.pmrj.2010.03.025

8. L. Gong, Y. Xiao, Ch. Jiang, Sh. Zheng, X. Fu, Seaport investments in capacity and natural disaster prevention, Transportation Research Part D: Transport and Environment 85, 102367 (2020) https://doi.org/10.1016/j.trd.2020.102367

9. R. Sharon, A.B. Weeks, L. Caitlin, B.S. McAuliffe, et. al. Physiological and Psychological Fatigue in Extreme Conditions: The Military Example PM\&R 2, 5, 438441 (2010) https://doi.org/10.1016/j.pmrj.2010.03.023

10. Yu.L. Yeryomkin, The effect of stress on psychological health, methods for measuring stress factors and coping ability with stress, Theory and methods of studying the psychological characteristics of production in the system for the prevention of technological disasters (Monograph, ed. L.A. Baykova; Ryaz.gos.un-t them. S.A. Yesenina, 111-125, 2008) 